\section{A) Check for updates}

Cite this: Dalton Trans., 2021, 50 12583

\title{
Mixed $\mathrm{H}_{2} \mathrm{O} / \mathrm{H}_{2}$ plasma-induced redox reactions of thin uranium oxide films under UHV conditions $\uparrow$
}

\author{
Ghada El Jamal, (D) *a Thomas Gouder, ${ }^{\text {b }}$ Rachel Eloirdi, ${ }^{\mathrm{b}}$ \\ Evgenia Tereshina-Chitrova, ${ }^{c, d}$ Lukáš Horákd $^{d}$ and Mats Jonsson (iD ${ }^{a}$
}

\begin{abstract}
X-ray photoelectron spectroscopy (XPS) has been used to study the effect of mixed $\mathrm{H}_{2} \mathrm{O} / \mathrm{H}_{2}$ gas plasma on the surfaces of $\mathrm{UO}_{2}, \mathrm{U}_{2} \mathrm{O}_{5}$ and $\mathrm{UO}_{3}$ thin films at $400{ }^{\circ} \mathrm{C}$. The experiments were performed in situ under ultra-high vacuum conditions. Deconvolution of the $U 4 f_{7 / 2}$ peaks into $U(I V), U(v)$ and $U(v)$ components revealed the surface composition of the films after 10 min plasma exposure as a function of $\mathrm{H}_{2}$ concentration in the feed gas of the plasma. Some selected films (unexposed and exposed) were also analysed using grazing-incidence $X$-ray diffraction (GIXRD). The XPS results show that $U(v)$ is formed as a major product upon 10 minutes exposure of $\mathrm{UO}_{3}$ by a mixed $\mathrm{H}_{2} \mathrm{O} / \mathrm{H}_{2}$ plasma in a fairly wide $\mathrm{H}_{2}$ concentration range. When starting with $U(v)\left(U_{2} \mathrm{O}_{5}\right)$, rather high $\mathrm{H}_{2}$ concentrations are needed to reduce $U(\mathrm{v})$ to $\mathrm{U}(\mathrm{IV})$ in 10 minutes. In the plasma induced oxidation of $\mathrm{UO}_{2}, \mathrm{U}(\mathrm{V})$ is never observed as a major product after 10 minutes and it would seem that once $\mathrm{U}(\mathrm{v})$ is formed in the oxidation of $\mathrm{UO}_{2}$ it is rapidly oxidized further to $U(\mathrm{VI})$. The grazing incidence $X$-ray diffraction analysis shows that there is a considerable impact of the plasma and heating conditions on the crystal structure of the films in line with the change of the oxidation state. This structural difference is proposed to be the main kinetic barrier for plasma induced transfer between $U(\mathrm{IV})$ and $U(\mathrm{v})$ in both directions.
\end{abstract}

Received 27th March 2021

Accepted 29th June 2021

DOI: $10.1039 / \mathrm{d} 1 \mathrm{dt} 01020 \mathrm{~d}$

rsc.li/dalton emitted by the fuel and absorbed by the adjacent groundwater (in the event of canister failure) will induce water radiolysis producing oxidizing $\left(\mathrm{H}_{2} \mathrm{O}_{2},{ }^{\circ} \mathrm{OH}, \mathrm{HO}_{2}{ }^{\circ}\right)$ and reducing species $\left(\mathrm{H}_{2}, \mathrm{H}^{*}, \mathrm{e}_{\mathrm{aq}}{ }^{-}\right) \cdot{ }^{6,7}$ Since the fuel matrix is mainly in its reduced form $(\mathrm{U}(\mathrm{Iv}))$, the radiolytic oxidants will initially dominate the chemistry at the fuel surface and drive the oxidative dissolution process where the fission products and actinides will subsequently be released. ${ }^{8}$ In the process of anaerobic corrosion of iron in the canister, large quantities of $\mathrm{H}_{2}$ will be produced. ${ }^{9,10} \mathrm{H}_{2}$ has been shown to efficiently inhibit the radiation driven oxidative dissolution of used nuclear fuel, ${ }^{11-14}$ an effect that can mainly be attributed to $\varepsilon$-particle catalysed reduction of oxidized uranium in the fuel matrix. ${ }^{15,16}$ The reduction competes with the dissolution of oxidized uranium but becomes dominating at fairly low $\mathrm{H}_{2}$ concentrations. The other inhibiting effect of $\mathrm{H}_{2}{ }^{15,17-26}$ is the impact it has on water radiolysis. $\mathrm{H}_{2}$ reacts with hydroxyl radicals producing $\mathrm{H}_{2} \mathrm{O}$ and hydrogen atoms. This reduces the yield of oxidants and increases the yield of reductants and thereby reduces the rate of oxidative dissolution.

As dissolution and precipitation of secondary phases occur in parallel with the redox processes, it is difficult to draw reliable mechanistic conclusions for the individual processes from experiments performed in solution. To circumvent this problem, we have recently developed an approach to simulate the radiolysis by a vacuum ECR (electron cyclotron resonance) 
water plasma (the products are to a large extent the same as the aqueous radiolysis products) to which we expose uranium oxide model films. In situ X-ray photoelectron spectroscopy (XPS) analysis was used to monitor the evolution of the freshly reacted surfaces, without interference of laboratory atmosphere, dissolution or precipitation reactions. Our previous work using this methodology has shown that a pure water plasma oxidizes $\mathrm{UO}_{2}$ and $\mathrm{U}_{2} \mathrm{O}_{5}(\mathrm{U}(\mathrm{v}))$ to $\mathrm{UO}_{3}(\mathrm{U}(\mathrm{vI}))$. In a series of exposures of $\mathrm{UO}_{2}$ films to the water plasma for different times we could evaluate the dynamics of the process. The results showed that $\mathrm{UO}_{2}$ is initially oxidized to $\mathrm{U}(\mathrm{v})$ and $\mathrm{U}(\mathrm{vI})$ and the latter becomes the major product after 10-15 minutes exposure. For longer exposures, $\mathrm{U}(\mathrm{vI})$ is slowly reduced back to $\mathrm{U}(\mathrm{v})$. These findings were discussed in detail and a simple kinetic model was developed to describe the dynamics of the process. ${ }^{27}$ While we have previously only used this methodology for exposures to pure water plasma, ${ }^{28}$ we have extended in the present study the experimental conditions by using a mixed $\mathrm{H}_{2} \mathrm{O} / \mathrm{H}_{2}$ plasma.

The use of a mixed $\mathrm{H}_{2} \mathrm{O} / \mathrm{H}_{2}$ plasma does not simply mimic the impact of $\mathrm{H}_{2}$ on water radiolysis since, in water radiolysis, the radiation energy is completely absorbed by water and $\mathrm{H}_{2}$ only reacts with the aqueous radiolysis products. In the mixed plasma, the plasma is generated both from $\mathrm{H}_{2} \mathrm{O}$ and $\mathrm{H}_{2}$ and the products may react with each other inside the plasma generator, while outside the plasma generator the pressure is too low to allow bimolecular processes before the plasma products reach the oxide surface. The use of a mixed $\mathrm{H}_{2} \mathrm{O} / \mathrm{H}_{2}$ plasma enables fine-tuning of the redox properties of the plasma, which opens up the possibility for more detailed studies of the redox chemistry of uranium oxide films under UHV conditions.

In this work, we have exposed $\mathrm{UO}_{2}, \mathrm{U}_{2} \mathrm{O}_{5}$ and $\mathrm{UO}_{3}$ films to mixed $\mathrm{H}_{2} \mathrm{O} / \mathrm{H}_{2}$ plasmas and analysed the films after $10 \mathrm{~min}$ plasma exposure using XPS complemented by grazing-incidence x-ray diffraction (GIXRD). The results are discussed in terms of intrinsic kinetic barriers for the transfer between different oxidation states.

\section{Experimental}

\section{Sample preparation}

Uranium oxide $\mathrm{UO}_{2.0}$ films were prepared in situ using optimized conditions of direct current (DC) sputtering from a uranium metal target in a gas mixture of $\operatorname{Ar}(6 \mathrm{~N})$ and $\mathrm{O}_{2}(5 \mathrm{~N})$. The Ar pressure used was $5 \times 10^{-3} \mathrm{mbar}$ and the $\mathrm{O}_{2}$ pressure ranged between $10^{-6} \mathrm{mbar}$ and $2 \times 10^{-6} \mathrm{mbar}$. The uranium target voltage was fixed at $-700 \mathrm{~V}$. The films of $20 \mathrm{~nm}$ thickness were deposited at $400{ }^{\circ} \mathrm{C}$ on polycrystalline Au substrates, cleaned by annealing to $200{ }^{\circ} \mathrm{C}$ for $10 \mathrm{~min}$. The deposition time was $15 \mathrm{~min}$. The plasma in the diode source was maintained by injecting electrons of 25-50 eV energy (triode setup), allowing working at a low Ar pressure in the absence of stabilizing magnetic fields. $\mathrm{UO}_{3}$ films were prepared by exposing the $\mathrm{UO}_{2}$ films to the oxygen plasma produced by the electron cyclotron resonance (ECR) source.

\section{ECR plasma source}

In the ECR source, the excitation of electrons is based on stochastic heating by microwave radiation in magnetic fields produced by permanent magnets. The electrons gain sufficient energy to ionize the gas and sustain the plasma when the resonance condition between the electrons and the microwave electric field is fulfilled. A reactive plasma environment is formed of excited species, free radicals, and ions. The temperature of samples during exposure was maintained at $400{ }^{\circ} \mathrm{C}$ using a pyrolytic boron nitride (PBN) heater installed below the sample holder. The water vapour used as a feed gas was in some cases mixed with $\mathrm{H}_{2}$ gas. Gas pressures were kept constant by a flowmeter setup to ensure stable plasma conditions.

More details about the ECR source and different gas plasma characterization methods with a RGA-Mass spectrometer are reported in a previous study. ${ }^{29}$

\section{Surface characterisation}

High-resolution X-ray photoelectron spectroscopy (XPS) was used to analyse the chemical surface composition of the films before and after each treatment. The spectra were obtained using a Specs Phoibos 150 hemispherical analyser, using $\mathrm{Al}-\mathrm{K} \alpha$ (1486.6 eV) radiation, produced by an XRC-1000 $\mu$-focus source, equipped with a monochromator and operating at 120 $\mathrm{W}$. The background pressure in the analysis chamber was $2 \times$ $10^{-10}$ mbar. The Au4f $\mathrm{f}_{7 / 2}$ line of the Au metal (83.9 eV BE) and the $\mathrm{Cu}-2 \mathrm{p}_{3 / 2}$ line of the $\mathrm{Cu}$ metal (932.7 eV BE) were used for calibration of binding energies. Photoemission spectra were taken at room temperature. The spectra obtained at high resolution were analysed by deconvolution into simple components. The $\mathrm{U}_{4} \mathrm{f}_{7 / 2}$ components were fitted to Gaussian/ Lorentzian functions. In all cases, a standard Shirley baseline was employed to separate the real signal from the background. The deconvolutions have been carried out by using XPS peak41 software.

\section{Grazing incidence X-ray diffraction}

The grazing incidence X-ray diffraction (GIXRD) measurements were carried out on a Rigaku SmartLab diffractometer using a $9 \mathrm{~kW}$ copper rotating anode $\mathrm{X}$-ray source $(\mathrm{Cu}-\mathrm{K} \alpha$ radiation $\lambda=$ $0.15418 \mathrm{~nm})$. It was equipped with a parabolic multilayer mirror in the primary beam, a set of axial divergence eliminating Soller slits in both the incident and diffracted beam (acceptance $5^{\circ}$ ) and a parallel beam Soller slit collimator (acceptance $0.5^{\circ}$ ). A HighPix-3000 2D hybrid pixel single photon-counting detector was located in the diffracted beam. The constant incidence angle of the primary beam $\omega=3.0^{\circ}$ was used for the measurement. Origin 2019b was used to retrace the figures. ICSD database was used to assign the different phases present in the films.

\section{Results and discussion}

Before discussing the impact of the mixed $\mathrm{H}_{2} \mathrm{O} / \mathrm{H}_{2}$-plasmas on uranium oxide films, it is important to understand the impact 
of pure plasmas. In two recent papers, it was shown that a pure $\mathrm{H}_{2} \mathrm{O}$ plasma oxidizes both $\mathrm{UO}_{2}$ and $\mathrm{U}_{2} \mathrm{O}_{5}$ to $\mathrm{UO}_{3}$ in $10 \mathrm{~min}$ at a sample temperature of $400{ }^{\circ} \mathrm{C}$. For longer exposures of $\mathrm{UO}_{2}$ to a pure $\mathrm{H}_{2} \mathrm{O}$ plasma it was shown that the $\mathrm{UO}_{3}$ formed initially and was slowly reduced back to $\mathrm{U}_{2} \mathrm{O}_{5}$. It has also recently been shown that $\mathrm{UO}_{3}$ exposed to a pure $\mathrm{H}_{2}$ plasma at a sample temperature of $400{ }^{\circ} \mathrm{C}$ for $10 \mathrm{~min}$ was quantitatively converted to $\mathrm{UO}_{2} \cdot{ }^{30}$ Exposing $\mathrm{U}_{2} \mathrm{O}_{5}$ to a pure $\mathrm{H}_{2}$ plasma under the same conditions also leads to the formation of $\mathrm{UO}_{2}$ while exposing $\mathrm{UO}_{2}$ to a pure $\mathrm{H}_{2}$ plasma leaves the oxide film unchanged.

In this paper, we perform all plasma exposures for $10 \mathrm{~min}$ and at a sample temperature of $400{ }^{\circ} \mathrm{C}$. Based on that found in the previous studies, the plasma-induced reactions are well advanced but not necessarily complete after $10 \mathrm{~min}$. Nevertheless, the use of a common exposure time for all oxides and plasma compositions allows direct comparison of the results.

\section{Properties of mixed $\mathrm{H}_{2} \mathrm{O} / \mathrm{H}_{2}$ plasma}

Before discussing the impact of the mixed $\mathrm{H}_{2} \mathrm{O} / \mathrm{H}_{2}$ plasma on different uranium oxides, it is necessary to address the properties of the mixed plasma. Hydrogen is introduced into the plasma chamber together with water and both gases are subjected to the ECR plasma. Fig. 1 shows the evolution of three crucial gas species, $\mathrm{O}_{2}, \mathrm{H}_{2} \mathrm{O}$ and $\mathrm{H}_{2}$, as the plasma is switched on and the hydrogen partial pressure is gradually increased. The RGA-Mass spectrometer is placed outside the plasma generator and only detects species escaping the plasma generator. As the pressure is very low, the probability for bimolecular reactions between plasma constituents outside the plasma generator is very low. Consequently, the detected products will reflect chemistry inside the plasma generator.

Before the plasma is switched on and while the plasma chamber is loaded with pure $\mathrm{H}_{2} \mathrm{O}$, only water is detected.

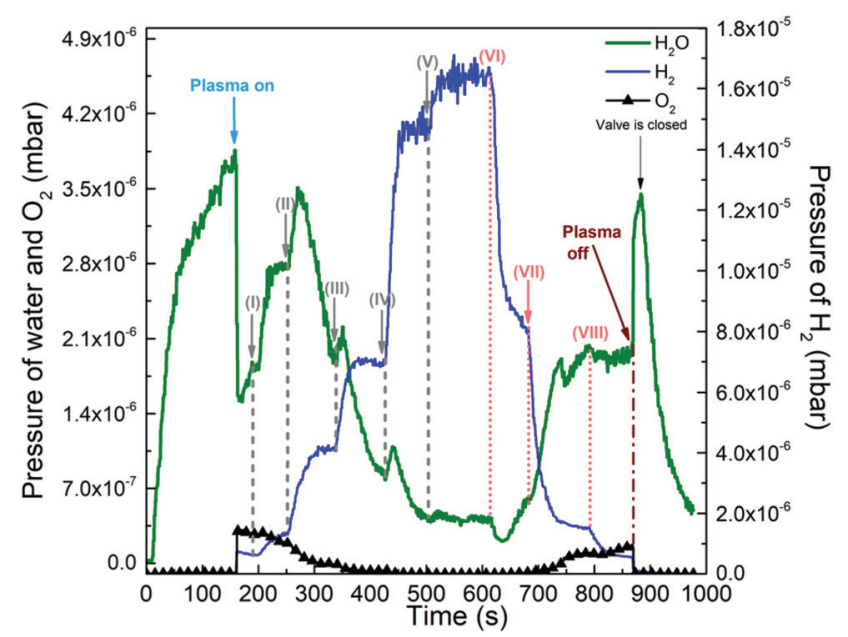

Fig. 1 Pressures of molecular products in a mixed $\mathrm{H}_{2} \mathrm{O} / \mathrm{H}_{2}$ plasma in a system where the $\mathrm{H}_{2}$ pressure in the plasma generator is first stepwise increased and thereafter stepwise decreased.
When the plasma is switched on the water signal decreases and $\mathrm{H}_{2}$ and $\mathrm{O}_{2}$ are also detected. These two products originate from the recombination of $\mathrm{H}$ atoms and $\mathrm{O}$ atoms, respectively. Both $\mathrm{H}$ atoms and $\mathrm{O}$ atoms are produced in a water plasma (in addition to hydroxyl radicals). After $200 \mathrm{~s}, \mathrm{H}_{2}$ is added to the plasma chamber with a relatively low partial pressure(I). The immediate response of the system is a slight decrease in the $\mathrm{O}_{2}$ pressure, a slight increase in the $\mathrm{H}_{2}$ pressure and a significant increase in the $\mathrm{H}_{2} \mathrm{O}$ pressure. After $250 \mathrm{~s}$ the partial pressure of $\mathrm{H}_{2}$ is increased for the second time (II). The immediate response is a further decrease in the $\mathrm{O}_{2}$ pressure, an increase in the $\mathrm{H}_{2}$ pressure and a rapid initial increase in the $\mathrm{H}_{2} \mathrm{O}$ pressure followed by an even larger drop in the pressure. This pattern is reproduced, although with a smaller initial increase and the following decrease in the $\mathrm{H}_{2} \mathrm{O}$ pressure for the following three incremental steps in the $\mathrm{H}_{2}$ pressure (III, IV, and V). The transient behaviour of $\mathrm{H}_{2} \mathrm{O}$ could partly be due to a slow response of the system when the $\mathrm{H}_{2}$ pressure is increased. After the third incremental increase in the $\mathrm{H}_{2}$ pressure, the $\mathrm{O}_{2}$ pressure is insignificant. The $\mathrm{H}_{2}$ supply is thereafter reduced in three steps (VI, VII, and VIII) and the system gradually recovers from the impact of $\mathrm{H}_{2}$ in the plasma generator. The decrease in the $\mathrm{O}_{2}$ pressure with increasing $\mathrm{H}_{2}$ pressure is partly due to the direct reaction between the $\mathrm{O}$ atom and $\mathrm{H}_{2}$ producing water, and the reaction between the $\mathrm{O}$ atom and the $\mathrm{H}$ atom producing hydroxyl radical. The gradual increase in the $\mathrm{H}_{2}$ pressure will also have an impact on the energy deposition in the plasma, and as the $\mathrm{H}_{2}$ pressure increases the primary production of the water plasma products will decrease. The consequence of this is that the oxidant concentration decreases both in absolute and relative terms with increasing $\mathrm{H}_{2}$ pressure. When increasing the $\mathrm{H}_{2}$ fraction in the plasma chamber of a mixed $\mathrm{H}_{2} \mathrm{O} / \mathrm{H}_{2}$ plasma, the plasma changes from containing both oxidants and reductants to a purely reducing plasma.

\section{$\mathrm{UO}_{2}$}

A number of $\mathrm{UO}_{2}$ films prepared by sputter deposition were exposed to mixed $\mathrm{H}_{2} \mathrm{O} / \mathrm{H}_{2}$ gas plasmas under the standard conditions (10 min exposure at $400{ }^{\circ} \mathrm{C}$ ) and characterized by means of XPS. The U4f, O1s, and valence band regions of the samples before and after exposure were mutually compared. The resulting U4f spectra are shown in Fig. 2. At 0, 3, and 10\% $\mathrm{H}_{2}$, the core level peaks shift towards higher binding energy as compared to the reference lines of the precursor $\mathrm{UO}_{2}$. For the pure water plasma reaction $\left(0 \% \mathrm{H}_{2}\right)$, this was attributed previously $^{28}$ to a chemical shift showing the oxidation of $\mathrm{UO}_{2}$ $(\mathrm{U}(\mathrm{IV}))$ into $\mathrm{UO}_{3}(\mathrm{U}(\mathrm{VI}))$. A quite similar effect is observed for 3 and $10 \% \mathrm{H}_{2}$. However, at $20 \% \mathrm{H}_{2}$, the core level peak is similar to that of $\mathrm{UO}_{2}$. A more detailed view reveals that it is broadened, developing intensity at low binding energy (BE), and positioned between the peaks of $\mathrm{UO}_{3}$ and $\mathrm{UO}_{2}$. This gives a first hint of the formation of an intermediate oxidation state $(\mathrm{U}(\mathrm{v}))$.

Besides the main lines, a convenient indicator of the oxidation state is the satellites on the high binding energy side. 


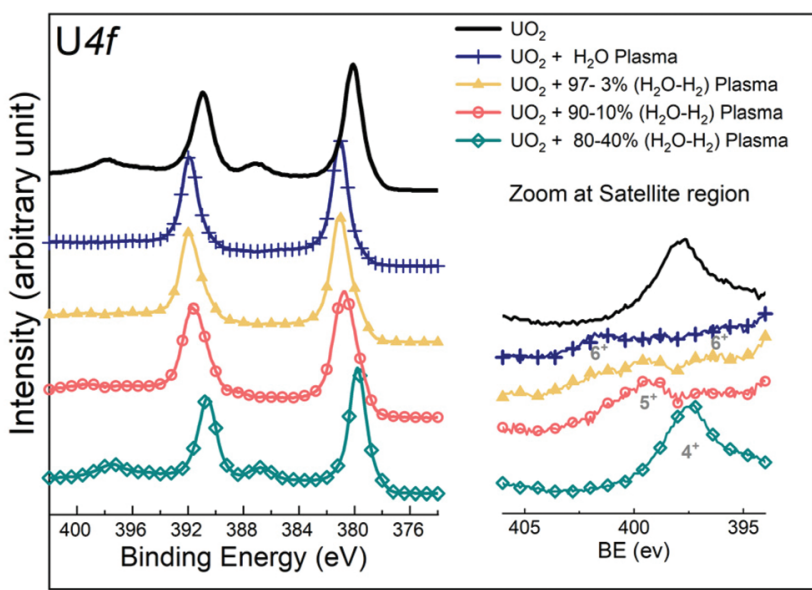

Fig. 2 U 4f core level X-ray photoemission spectra of uranium recorded for the precursor $\mathrm{UO}_{2}$ film and for the $\mathrm{UO}_{2}$ films exposed to pure water plasma and a mixed gas plasma of water and hydrogen.

Although their intensities are much lower compared to the main lines, they can much better resolve individual species. In Fig. 2 (right), when the $\mathrm{UO}_{2}$ film is exposed to a pure water plasma, the typical satellite peak of $\mathrm{U}(\mathrm{vI})$ appears. With increasing $\mathrm{H}_{2}$ concentration up to $10 \%$ (hereafter referred to as $10 \% \mathrm{H}_{2}$ in the $\mathrm{H}_{2} \mathrm{O} / \mathrm{H}_{2}$ mixed plasma) in the mixed gas plasma, it is gradually replaced by the $\mathrm{U}(\mathrm{v})$ satellite peak. At $20 \% \mathrm{H}_{2}$ in a mixed plasma, the satellite peak of $\mathrm{U}(\mathrm{IV})$ is finally formed. These data consistently show a decreasing oxidation power of the water plasma with increasing $\mathrm{H}_{2}$ content.

The valence band spectra and O1s peaks of the plasmaexposed $\mathrm{UO}_{2}$ films are plotted in Fig. 3. Regardless of the $\mathrm{H}_{2}$ concentration, the intensity of the U5f peak originally present at $1.2 \mathrm{eV}$ below the Fermi level decreases after the exposure. We have previously concluded that the loss of the U5f intensity is due to the occupancy of the $5 \mathrm{f}$ states decreasing with uranium oxidation (nominally 2 for $\mathrm{U}(\mathrm{IV}), 1$ for $\mathrm{U}(\mathrm{v})$ and 0 for

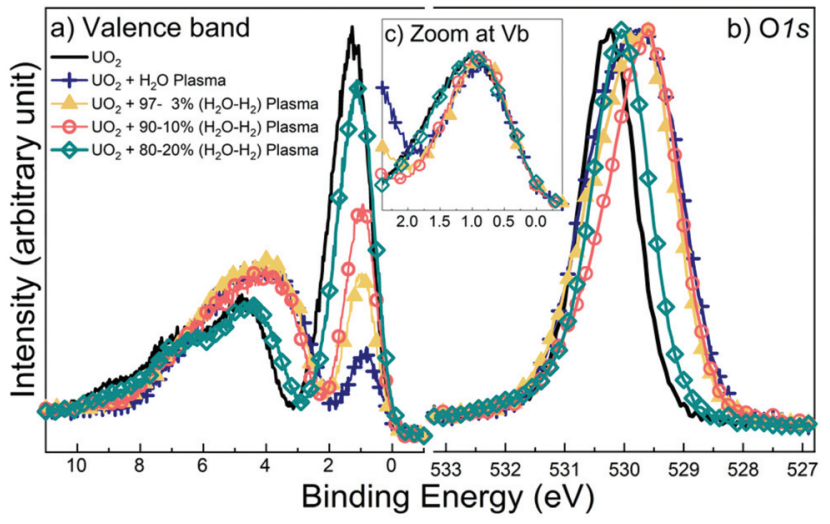

Fig. 3 X-ray photoemission spectra of the valence band (a) and O1s core level line (b) recorded for the precursor and plasma treated films. Panel (c) captures the details of the $5 f$ states normalized and shifted in energy for comparison as described in the text. Films exposed to pure water plasma and a mixed gas plasma of water and hydrogen.
$\mathrm{U}(\mathrm{vI})) .{ }^{30}$ The intensity loss is strongest for the pure water plasma exposure, pointing to strong oxidation (close to $\mathrm{U}(\mathrm{vI})$ ). Even when the $\mathrm{H}_{2}$ concentration in the plasma feed gas is as low as $3 \%$, the U5f intensity is much higher compared to the peak observed for the pure water plasma exposure. At $20 \% \mathrm{H}_{2}$, the intensity is almost the same as for the unexposed film. This shows that the oxidizing effect of the water plasma is suppressed by hydrogen, up to the point that practically no oxidation takes place at $20 \% \mathrm{H}_{2}$. In Fig. $3 \mathrm{c}$ the U5f bands are normalized to the same height and shifted to the same lower binding energy side for easier comparison. The spectra can be divided into two groups. One group contains broad peaks and is observed for the untreated and $20 \% \mathrm{H}_{2}$ in the $\mathrm{H}_{2} \mathrm{O} / \mathrm{H}_{2}$ mixed plasma films. The other group has narrow peaks and is observed for all other plasma processed films. The different peak widths are attributed to the different $5 \mathrm{f}$ counts, leading to different final state multiplets: the broad shape corresponds to the $5 \mathrm{f}^{2}$ ground state of U(Iv) while the narrow peak corresponds to the $5 \mathrm{f}^{1}$ ground state of $\mathrm{U}(\mathrm{v})$. This shows that for the 0,3 , and $10 \% \mathrm{H}_{2}$ treated films, $\mathrm{UO}_{2}$ is oxidized into a mixture of $\mathrm{U}(\mathrm{v})$ (giving $5 \mathrm{f}^{1}$ ) and $\mathrm{U}(\mathrm{vI})$ (giving no peaks at all because of the $5 \mathrm{f}^{0}$ configuration). The result is a pure $5 \mathrm{f}^{1}$ signal. For $20 \%$ $\mathrm{H}_{2}$ in a mixed plasma almost no oxidation takes place and the pure $5 \mathrm{f}^{2}$ is observed, just as for the untreated film. All the plasma treated films have a featureless and broad $\mathrm{O} 2 \mathrm{p}$ band (dominating the valence band spectra in the energy range 3-7 $\mathrm{eV}$ ), except the one exposed to the $20 \% \mathrm{H}_{2}$ in a mixed plasma, which exhibits the same two-peak shape and low intensity as $\mathrm{UO}_{2}$ (observed for the untreated films).

The observed evolution of the $\mathrm{U}$ oxidation state is corroborated by the $\mathrm{O} 1 \mathrm{~s}$ spectra for different treatment conditions (Fig. 3b). The O1s signal of the original $\mathrm{UO}_{2}$ film lies at 530.1 $\mathrm{eV}$. When the film is exposed to a pure $\mathrm{H}_{2}$ plasma under the conditions used in this work, the resulting XPS spectra are identical to $\mathrm{UO}_{2}$, proving that the oxide is unchanged. After exposure to the pure water plasma, the O1s signal strongly broadens and shifts towards the lower binding energy, as expected for $\mathrm{UO}_{3}$. Moreover, it acquires the shape typical of $\mathrm{UO}_{3} \cdot{ }^{30}$ The broadening is attributed to the crystal structure of $\mathrm{UO}_{3}$, having inequivalent oxygen atoms (in contrast to $\mathrm{UO}_{2}$ ). With increasing hydrogen concentration, the broadening becomes less pronounced. The O1s peak width after exposure to $10 \% \mathrm{H}_{2}$ in mixed plasma is between the $\mathrm{O} 1 \mathrm{~s}$ peak widths observed for $\mathrm{UO}_{3}$ and $\mathrm{UO}_{2}$. This is typical of $\mathrm{U}_{2} \mathrm{O}_{5}$, as shown previously. ${ }^{30}$ The sample exposed to $20 \% \mathrm{H}_{2}$ in mixed plasma has an O1s peak of the same width as the original $\mathrm{UO}_{2}$, but only slightly shifted to the lower binding energy (by $-0.3 \mathrm{eV}$ ).

$\mathrm{UO}_{3}$

Thin films of $\mathrm{UO}_{3}$ were prepared by exposing $\mathrm{UO}_{2}$ films to atomic oxygen at $400{ }^{\circ} \mathrm{C}$ for $10 \mathrm{~min}$. The preparation procedure has been described in detail in a previous paper. ${ }^{30}$ Each film was then exposed to a mixed $\mathrm{H}_{2} \mathrm{O} / \mathrm{H}_{2}$ plasma at $400{ }^{\circ} \mathrm{C}$ for $10 \mathrm{~min}$. The corresponding regions of U4f probed with XPS are presented in Fig. 4. 


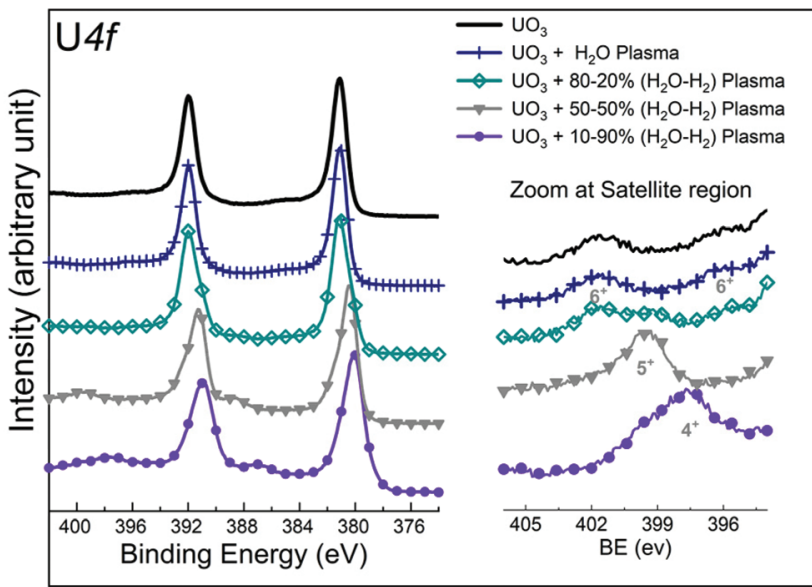

Fig. 4 U4f core level XPS spectra recorded for the precursor $\mathrm{UO}_{3}$ film and the films with plasma treatment.

It was shown previously that $\mathrm{UO}_{3}$ is prone to reduction when exposed to pure water plasma. ${ }^{28}$ This was attributed to the atomic hydrogen, also being present in the pure water plasma. The effect is, though, very weak and longer exposure times than used in the present study are needed (30-60 min (ref. 27)) to observe partial reduction of $\mathrm{U}(\mathrm{vI})$ into $\mathrm{U}(\mathrm{v})$. For mixed $\mathrm{H}_{2} \mathrm{O} / \mathrm{H}_{2}$ plasma, the reduction becomes more pronounced.

The U4f peaks shift to lower binding energy and broaden: the $\mathrm{U}(\mathrm{v})$ component grows at the expense of the $\mathrm{U}(\mathrm{vI})$ component at higher BE. After exposure to $20 \% \mathrm{H}_{2}$ in a mixed plasma the $\mathrm{U}(\mathrm{vI})$ component is still the dominating peak, while after exposure to $50 \% \mathrm{H}_{2}$ in a mixed plasma the $\mathrm{U}(\mathrm{v})$ peak becomes the most prominent one. After exposure to the $20 \%$ $\mathrm{H}_{2}$ in a mixed plasma, the satellite peak of $\mathrm{U}(\mathrm{v})$ appears. For exposures to $30 \% \mathrm{H}_{2}$ or higher $\mathrm{H}_{2}$ concentration, the $\mathrm{U}(\mathrm{v})$ satellite completely replaces the U(vI) satellite (data not shown). For the sake of clarity, we only plotted the result for the film exposed to $50 \% \mathrm{H}_{2}$ in a mixed plasma.

At still higher $\mathrm{H}_{2}$ concentrations, the surface is further reduced and the $\mathrm{U}(\mathrm{Iv})$ satellite appears. However the reduction is not complete even for $90 \% \mathrm{H}_{2}$, and a residual $\mathrm{U}(\mathrm{v})$ satellite remains. It is only when the $\mathrm{UO}_{3}$ film is exposed to a pure $\mathrm{H}_{2}$ plasma that it is fully reduced to $\mathrm{U}(\mathrm{Iv})$.

The valence band and $\mathrm{O} 1 \mathrm{~s}$ spectra for the $\mathrm{UO}_{3}$ films exposed to mixed $\mathrm{H}_{2} \mathrm{O} / \mathrm{H}_{2}$ plasmas are plotted in Fig. 5. From these spectral features it is, as expected, evident that the degree of reduction increases with increasing $\mathrm{H}_{2}$ content of the mixed plasma. The O2p band loses its broad symmetrical shape, decreases in intensity and eventually takes the two-peak shape of $\mathrm{UO}_{2}$ (Fig. 3) after exposure to a mixed plasma containing $90 \% \mathrm{H}_{2}$. In addition, the U5f peak increases in intensity due to the enhanced $5 \mathrm{f}$ population (n5f) after the reduction of $\mathrm{U}(\mathrm{vI})$ to $\mathrm{U}(\mathrm{v})$ and then $\mathrm{U}(\mathrm{rv})$ (n5f $=0,1$ and 2, respectively). After exposure of pure $\mathrm{UO}_{3}$ to the mixed plasma the O1s signal is identical to the signal before exposure. With increasing $\mathrm{H}_{2}$ concentration, the O1s peak narrows and shifts towards higher

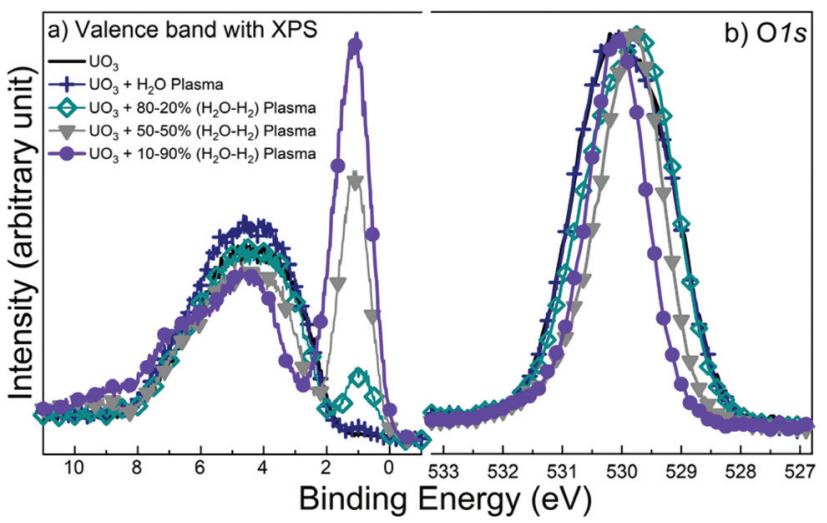

Fig. 5 a) Valence band and b) O1s core level XPS spectra for the precursor and plasma treated $\mathrm{UO}_{3}$ films.

binding energies. The exposure to $30 \% \mathrm{H}_{2}$ in a mixed plasma (not shown) yields a similar O1s spectrum for the $50 \% \mathrm{H}_{2}$ in a mixed plasma. This is attributed to the presence of an intermediate oxidation state $(\mathrm{U}(\mathrm{v}))$, stable over an extended range of reducing conditions. It is only when $\mathrm{UO}_{3}$ is exposed to $90 \% \mathrm{H}_{2}$ in a mixed plasma that the peak narrows even more and takes the shape typical of $\mathrm{UO}_{2}$.

$\mathbf{U}_{2} \mathbf{O}_{5}$

Films of pure $\mathrm{U}_{2} \mathrm{O}_{5}$ (where $\mathrm{U}(\mathrm{v})$ is the only oxidation state of uranium) have been prepared by exposing thin films of $\mathrm{UO}_{3}$ to $30 \% \mathrm{H}_{2}$ in a mixed plasma. The synthesized $\mathrm{U}_{2} \mathrm{O}_{5}$ films were subsequently exposed to a mixed $\mathrm{H}_{2} \mathrm{O} / \mathrm{H}_{2}$ plasma with variable feed gas compositions at $400{ }^{\circ} \mathrm{C}$ for $10 \mathrm{~min}$. The U4f spectra of these films are presented in Fig. 6. Pure water plasma has an oxidizing effect on $\mathrm{U}_{2} \mathrm{O}_{5}$, manifested by the shifted main line and the respective satellite, being a hallmark of $\mathrm{U}(\mathrm{vI}) .{ }^{30}$ When $\mathrm{H}_{2}$ is introduced in the feed gas of the plasma, the oxidation of $\mathrm{U}_{2} \mathrm{O}_{5}$ is less pronounced. After exposure to $20 \% \mathrm{H}_{2}$ in a mixed plasma, the $\mathrm{U}(\mathrm{vI})$ main line component is smaller than

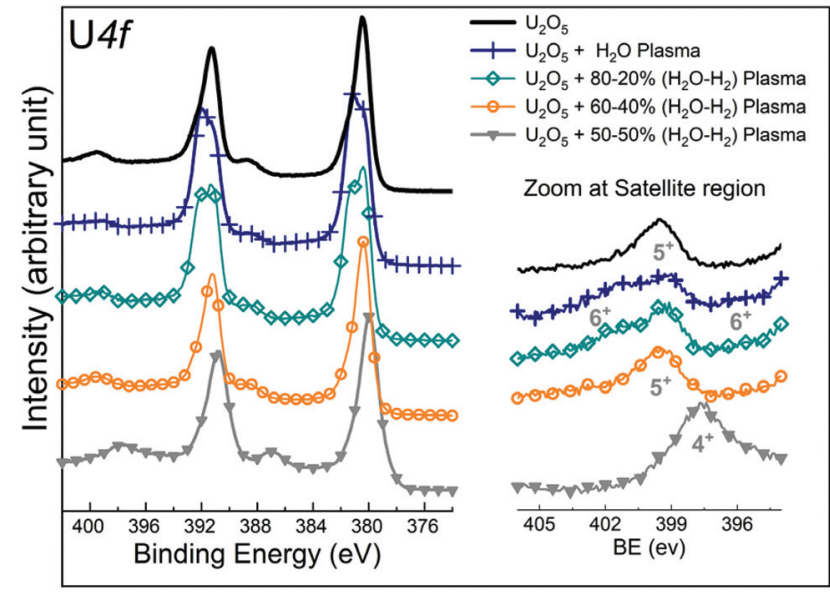

Fig. 6 U4f core level XPS spectra recorded for the original $\mathrm{U}_{2} \mathrm{O}_{5}$ film and $\mathrm{U}_{2} \mathrm{O}_{5}$ films exposed to plasma with variable $\mathrm{H}_{2} \mathrm{O}-\mathrm{H}_{2}$ composition. 
after exposure to the pure water plasma. In addition, the $\mathrm{U}(\mathrm{vI})$ satellite peak is less developed, and the $\mathrm{U}(\mathrm{v})$ satellite peak more intense. When $\mathrm{U}_{2} \mathrm{O}_{5}$ is exposed to $40 \% \mathrm{H}_{2}$ in a mixed plasma, the resulting $\mathrm{U} 4 \mathrm{f}$ is almost identical to the unexposed $\mathrm{U}_{2} \mathrm{O}_{5}$ film, showing only the $\mathrm{U}(\mathrm{v})$ satellite peak. After exposure to $50 \% \mathrm{H}_{2}$ in a mixed plasma, the U4f peaks undergo an additional shift towards lower binding energy, showing that uranium is now reduced to U(Iv). Accordingly, the satellite peak of $\mathrm{U}(\mathrm{Iv})$ replaces the $\mathrm{U}(\mathrm{v})$ satellite peak (Fig. 5). However, this reduction does not advance any further for the film exposed to $80 \% \mathrm{H}_{2}$ in a mixed plasma. Even though the $\mathrm{U}(\mathrm{IV})$ satellite line is solely present after exposure to $80 \% \mathrm{H}_{2}$ in a mixed plasma, the full width at half maximum of the main peak is larger than that for pure $\mathrm{UO}_{2}$. Hence, there is still a noticeable $\mathrm{U}(\mathrm{v})$ component in the main line (and a weak residual $\mathrm{U}(\mathrm{v})$ satellite peak may be masked by the strong U(Iv) satellite peak). This shows that the reduction is not complete.

The effect of plasma exposure is also evident in Fig. 7 where the XPS survey spectra of the valence band and the O1s peak of each exposed sample are presented. As discussed previously, ${ }^{28}$ after the oxidation of $\mathrm{U}_{2} \mathrm{O}_{5}$ with the water plasma, the intensity of the U5f peak at $1.2 \mathrm{eV}$ decreases without changing its width, which implies that the product after plasma exposure is a mixture of $\mathrm{U}(\mathrm{v})$ and $\mathrm{U}(\mathrm{v})$. $\mathrm{U}(\mathrm{v})$ gives the $5 \mathrm{f}^{1}$ signal while $\mathrm{U}(\mathrm{vI})$ has no $5 \mathrm{f}$ emission at all. $\mathrm{U}(\mathrm{v})$ can either oxidize or reduce, depending on the redox potential of the environment. With increasing $\mathrm{H}_{2}$ concentration, the reduction in the U5f intensity is much less pronounced than for the water plasma, which implies that $\mathrm{U}_{2} \mathrm{O}_{5}$ is less oxidized. Upon exposure to mixed plasmas with $50 \%$ or more $\mathrm{H}_{2}$, the U5f line grows and the $\mathrm{O} 2 \mathrm{p}$ band loses its broad shape and becomes similar to the characteristic spectrum of $\mathrm{UO}_{2} \cdot \mathrm{U}_{2} \mathrm{O}_{5}$ is clearly reduced under such conditions.

Fig. 7 also shows that the O1s peak of $\mathrm{U}_{2} \mathrm{O}_{5}$ becomes broader after exposure to the water plasma and shifts to lower binding energy. As discussed above, this indicates the oxidation of $\mathrm{U}_{2} \mathrm{O}_{5}$ into $\mathrm{UO}_{3}$. After exposure to $20 \% \mathrm{H}_{2}$ in a mixed plasma the peak is slightly narrower. After exposure to $40 \% \mathrm{H}_{2}$ in a mixed plasma, the O1s line becomes again narrower and superimposes to the original peak of $\mathrm{U}_{2} \mathrm{O}_{5}$, showing that the

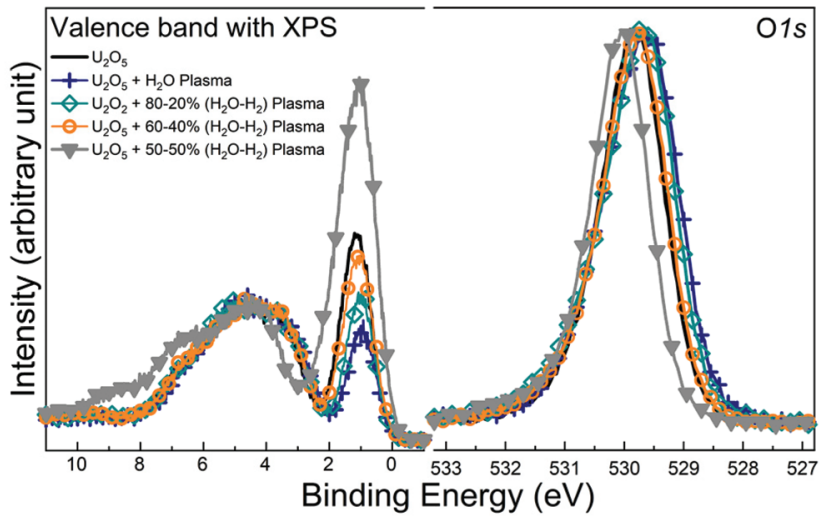

Fig. 7 Valence band and O1s XPS spectra recorded for unexposed and plasma treated $\mathrm{U}_{2} \mathrm{O}_{5}$ films. film does not react at all. For plasma containing $50-80 \% \mathrm{H}_{2}$, the O1s peak narrows even more and shifts to higher binding energy, characteristic of $\mathrm{UO}_{2}$.

\section{Oxidation state distribution as a function of $\mathrm{H}_{2}$ concentration}

To get more quantitative information, we deconvoluted individual $\mathrm{U}_{4} \mathrm{f}_{7 / 2}$ lines into the respective spectra of pure $\mathrm{UO}_{2}$, $\mathrm{U}_{2} \mathrm{O}_{5}$, and $\mathrm{UO}_{3}$. This gives fractions of $\mathrm{U}(\mathrm{rv}), \mathrm{U}(\mathrm{v})$, and $\mathrm{U}(\mathrm{vI})$ as a function of $\mathrm{H}_{2}$ concentration by the plasma treatment of $\mathrm{UO}_{2}$, $\mathrm{U}_{2} \mathrm{O}_{5}$, and $\mathrm{UO}_{3}$ precursors. The results are plotted in Fig. 8.

The relative fractions of $\mathrm{U}(\mathrm{Iv}), \mathrm{U}(\mathrm{v})$ and $\mathrm{U}(\mathrm{vI})$ after 10 minutes exposure to a mixed $\mathrm{H}_{2} \mathrm{O} / \mathrm{H}_{2}$ plasma as a function of $\mathrm{H}_{2}$ concentration in the plasma feeding gas provides interesting information on the uranium oxide and mixed plasma system. $\mathrm{UO}_{2}$ is shown to be oxidized by the mixed plasma provided the $\mathrm{H}_{2}$ content is below $40 \%$. In other words, $40 \% \mathrm{H}_{2}$ is sufficient to suppress oxidation by increasing the reduction rate of $\mathrm{U}(\mathrm{v})$ at the surface, in combination with decreasing the rate of $\mathrm{U}(\mathrm{Iv})$ oxidation (through increasing the flux of reductants and decreasing the flux of oxidants as seen in Fig. 1).

For $\mathrm{UO}_{3}$ it is obvious that reduction in the $10 \mathrm{~min}$ time scale occurs only in presence of $\mathrm{H}_{2}$. In general, the rate and extent of reduction appear to be increasing with increasing $\mathrm{H}_{2}$ concentration up to $30 \%$. Between 30 and $70 \% \mathrm{H}_{2}$ the major product is $\mathrm{U}(\mathrm{v})$ and the extent of reduction appears to be concentration independent. At around $90 \% \mathrm{H}_{2}$, reduction proceeds all the way to U(Iv) which becomes the major product.

As can be seen, the oxidation of $\mathrm{UO}_{2}$ and the reduction of $\mathrm{UO}_{3}$ proceed via the formation of $\mathrm{U}(\mathrm{v})$. Interestingly, $\mathrm{U}(\mathrm{v})$ $\left(\mathrm{U}_{2} \mathrm{O}_{5}\right)$ is quantitatively reduced to $\mathrm{U}(\mathrm{IV})$ at an $\mathrm{H}_{2}$ concentration

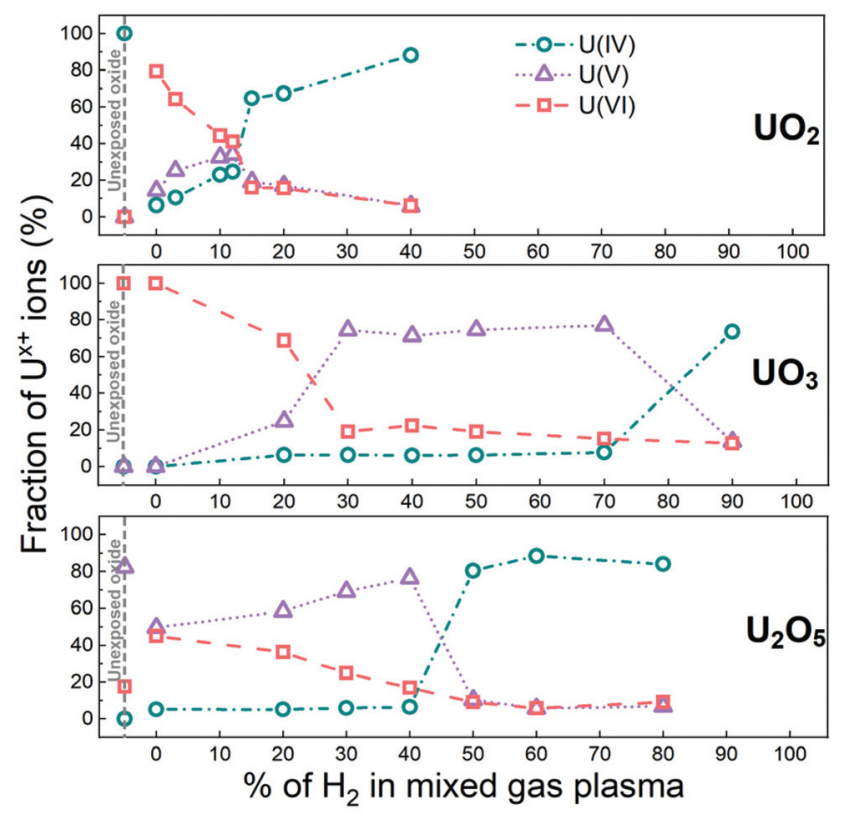

Fig. 8 Fractions of different uranium oxidation states (obtained by decomposition of the $\mathrm{U}_{4} \mathrm{f}_{7 / 2}$ spectra) as a function of $\mathrm{H}_{2}$ concentration in the plasma feed gas. The results from the unexposed films (marked by dashed lines) are included for comparison. 
of $50 \%$ and higher, while it is oxidized to $\mathrm{U}(\mathrm{vI})$ at an $\mathrm{H}_{2}$ concentration from around $40 \%$ and lower. The rate and extent of the oxidation reaction within the $10 \mathrm{~min}$ time scale increase with decreasing $\mathrm{H}_{2}$ concentration.

The fact that $\mathrm{U}(\mathrm{v})$ is never a major product after $10 \mathrm{~min}$ of $\mathrm{UO}_{2}$ oxidation while the reduction of $\mathrm{UO}_{3}$ involves $\mathrm{U}(\mathrm{v})$ as the major product in a wide $\mathrm{H}_{2}$ concentration range provides interesting information about the kinetics of the processes. As described above, long-term exposure of $\mathrm{UO}_{2}$ to a pure water plasma initially leads to oxidation affording $\mathrm{U}(\mathrm{v})$ and $\mathrm{U}(\mathrm{vI})$. After reaching a state of almost pure $\mathrm{U}(\mathrm{vI})$, prolonged exposure leads to the slow formation of U(v). Interestingly, UPS data (not shown here) being more surface sensitive than XPS reveal the formation of $\mathrm{U}(\mathrm{v})$ and $\mathrm{U}(\mathrm{vI})$ during the initial oxidation of $\mathrm{UO}_{2}$, but the slow formation of $\mathrm{U}(\mathrm{v})$ from $\mathrm{U}(\mathrm{vI})$ could never be confirmed by this method. Therefore, it was concluded that the $\mathrm{U}(\mathrm{v})$ formed upon reduction of $\mathrm{U}(\mathrm{vI})$ was formed deeper in the film and thereby displayed a lower reactivity towards the water plasma constituents. The present XPS data corroborate this hypothesis since the reduction of $\mathrm{UO}_{3}$ mainly yields $\mathrm{U}(\mathrm{v})$ in a very wide $\mathrm{H}_{2}$ concentration range and proceeds to $\mathrm{U}(\mathrm{Iv})$ only at around $90 \% \mathrm{H}_{2}$. At the same time, $\mathrm{U}_{2} \mathrm{O}_{5}$ exposed to mixed plasma is quantitatively already converted to $\mathrm{U}(\mathrm{IV})$ at $50 \% \mathrm{H}_{2}$, i.e., at a considerably lower reducing power.

\section{Grazing incidence X-ray diffraction}

It is naturally very interesting to compare the in situ spectroscopic information with results of ex situ structural study by X-ray diffraction. Fig. 9 displays grazing incidence X-ray diffraction (GIXRD) data for the $\mathrm{UO}_{2}$ film deposited on a gold substrate (pattern A) and for the $\mathrm{UO}_{2}$ film exposed to an oxygen plasma (pattern B) and a water plasma (pattern C). In pattern A, indexing the peaks to the structures of $\mathrm{UO}_{2}$ (ICSD\#35204, space group $F m \overline{3} m$ (no. 226), $a=5.4682(21)$ ) and gold (ICSD\#259286, space group $F m \overline{3} m$ (no. 226), $a=4.0787(1)$ ) is reported. GIXRD reveals that the $\mathrm{UO}_{2}$ film produced under the conditions used in this work is highly textured with a preferential orientation of the [111] direction perpendicular to the substrate plane. When the crystalline $\mathrm{UO}_{2}$ films (pattern $\mathrm{A}$ ) are oxidized to $\mathrm{UO}_{3}$ by the $\mathrm{O}_{2}$ plasma, the crystallinity is lost and
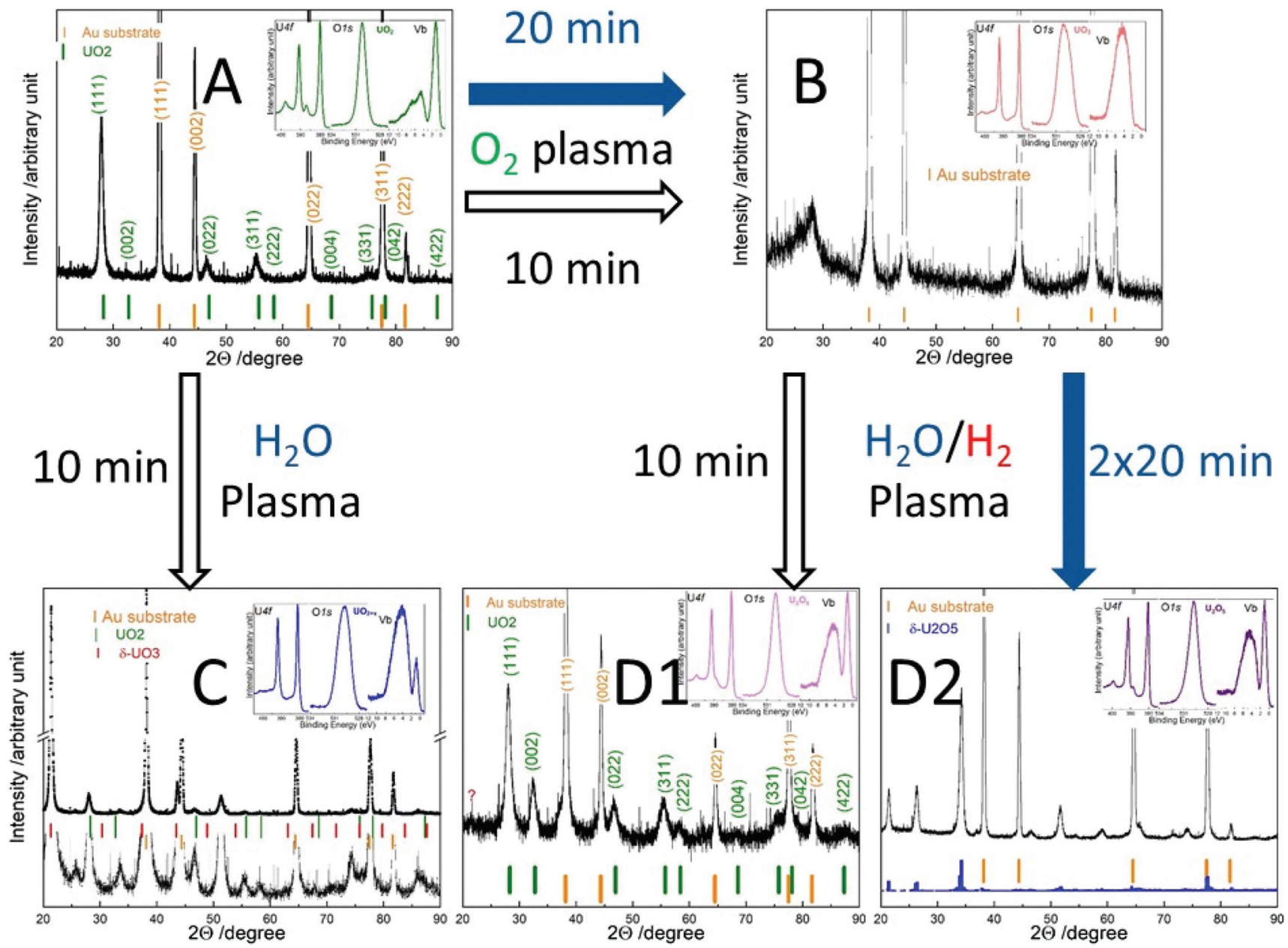

Fig. 9 Room-temperature grazing incidence XRD data of the $\mathrm{UO}_{2}$ film on $\mathrm{Au}$ substrate (A). $\mathrm{UO}_{3}$ is obtained by the oxidation of $\mathrm{UO}_{2}$ by atomic oxygen (B). Effects of mixed $30 \% \mathrm{H}_{2}$ in the mixed plasma (D1, D2) on the structure of $\mathrm{UO}_{3}$ are compared with $\mathrm{UO}_{2}$ kept in water plasma for 10 min (C). Insets in the figures show corresponding XPS data. 
the obtained $\mathrm{UO}_{3}$ film is amorphous (pattern B) after $10 \mathrm{~min}$, and remains amorphous also after $20 \mathrm{~min}$ exposure. Exposing the $\mathrm{UO}_{3}$ film to a mixed $30 \% \mathrm{H}_{2}$ in a mixed plasma for $10 \mathrm{~min}$ (pattern D1) or performing two consecutive exposures of 20 min duration (pattern D2) shows that the relative importance of oxidation and reduction reactions changes with the exposure time. A mixed plasma exposure for $10 \mathrm{~min}$ leads to the formation of the fluorite structure similar to $\mathrm{UO}_{2}$. After two consecutive 20 min exposures, pattern D2 changes to a completely different structure. A fit of the pattern was done with the structure of $\delta-\mathrm{U}_{2} \mathrm{O}_{5}$ (ICSD\#77702, Pmma, no. 51, $a=$ 31.71, $b=8.29, c=6.73)^{34}$ based on XPS-UPS analyses showing pure $\mathrm{U}(\mathrm{v})$. However as the orthorhombic structure of $\delta-\mathrm{U}_{2} \mathrm{O}_{5}$ is not very different from $\alpha-\mathrm{U}_{3} \mathrm{O}_{8},{ }^{35}$ the latter cannot be excluded by XRD analysis. The difference in the oxygen atom content and position in the lattice can be better analysed by the neutron diffraction technique. Other techniques such as micro-Raman spectroscopy ${ }^{36}$ to differentiate the uranium oxides present in the films would be also useful but maybe not sufficient to support the XRD analyses.

Oxidation of $\mathrm{UO}_{2}$ by the water plasma for $10 \mathrm{~min}$ (pattern C) shows that the $\mathrm{UO}_{2}$ concentration decreased substantially at a lower intensity peak at $28.04^{\circ}$ in $2 \theta$, while a new and highly textured phase is formed and characterized by a strong intensity peak at $21.48^{\circ}$. This peak could be assigned to cubic $\mathrm{UO}_{3}{ }^{37}$ whose Bragg positions are reported in the figure for comparison but it could be also linked to $\delta-\mathrm{U}_{2} \mathrm{O}_{5},{ }^{34} \alpha-\mathrm{U}_{3} \mathrm{O}_{8}{ }^{35}$ or $\beta-\mathrm{U}_{3} \mathrm{O}_{8} \cdot{ }^{38}$ The limited number of Bragg peaks and their low intensities prevents us from unambiguous identification of the crystal structure type. As suggested by the XPS-UPS results and in agreement with the XRD analysis, sample $\mathrm{C}$ is not pure and contains at least 2 phases of which only the cubic structure expected of $\mathrm{UO}_{2}$ can be clearly identified.

As has been shown in the spectral analysis above and in the tentative deconvolution, $\mathrm{U}(\mathrm{v})$ is formed as a major product upon the 10 min exposure of $\mathrm{UO}_{3}$ to a mixed $\mathrm{H}_{2} \mathrm{O} / \mathrm{H}_{2}$ plasma in a fairly wide $\mathrm{H}_{2}$ concentration range. When starting with $\mathrm{U}(\mathrm{v})\left(\mathrm{U}_{2} \mathrm{O}_{5}\right)$ it is evident that fairly high $\mathrm{H}_{2}$ concentrations are needed to reduce $\mathrm{U}(\mathrm{v})$ to $\mathrm{U}(\mathrm{Iv})$ in $10 \mathrm{~min}$. In the plasma induced oxidation of $\mathrm{UO}_{2}, \mathrm{U}(\mathrm{v})$ is never observed as a major product after $10 \mathrm{~min}$ and it seems that once $\mathrm{U}(\mathrm{v})$ is formed in the oxidation of $\mathrm{UO}_{2}$, it is oxidized further to $\mathrm{U}(\mathrm{vI})$. One possible explanation may be that compounds containing $\mathrm{U}(\mathrm{v})$ and $\mathrm{U}(\mathrm{vI})$ have similar crystal structures: $\mathrm{UO}_{3}, \mathrm{U}_{3} \mathrm{O}_{8}$ (a mixed oxide with $66 \% \mathrm{U}(\mathrm{v})$ and $33 \% \mathrm{U}(\mathrm{vr})$ ) and $\mathrm{U}_{2} \mathrm{O}_{5}$ (pure $\mathrm{U}(\mathrm{v})$ oxide) all exist in a layered structure (see the additional material), while $\mathrm{U}(\mathrm{Iv})$ mostly exists in a cubic (fluorite) structure. ${ }^{31-33}$ Because of the similarity in the crystal structure, reduction of $\mathrm{UO}_{3}$ to $\mathrm{U}_{3} \mathrm{O}_{8}$ then to $\mathrm{U}_{2} \mathrm{O}_{5}$ does not require any major structure reorganization. However, when oxidizing $\mathrm{UO}_{2}$ to $\mathrm{U}_{2} \mathrm{O}_{5}$ a major structural transformation is required. This is also the case when reducing $\mathrm{U}(\mathrm{v})$ to $\mathrm{U}(\mathrm{Iv})$. This would partly explain why the reduction of $\mathrm{UO}_{3}$ with mixed $\mathrm{H}_{2}$ in a mixed plasma appears to have $\mathrm{U}(\mathrm{v})$ as the major product after $10 \mathrm{~min}$ exposure within a wide range of $\mathrm{H}_{2}$ concentrations and why fairly high $\mathrm{H}_{2}$ concentrations are needed to reduce $\mathrm{U}_{2} \mathrm{O}_{5}$ to $\mathrm{U}(\mathrm{IV})$ within $10 \mathrm{~min}$.
The kinetic limitations would also account for the fact that $\mathrm{U}(\mathrm{v})$ is never observed as the major product in plasma induced oxidation of $\mathrm{UO}_{2}$. Given the fairly short exposure times used in this work, we can only rationalize the structural reorganization in terms of a kinetic barrier.

\section{Conclusions}

In this work, we have studied the impact of mixed $\mathrm{H}_{2} \mathrm{O} / \mathrm{H}_{2}$ plasma of variable composition on thin uranium oxide films under UHV conditions. The starting compositions of the films used were $\mathrm{UO}_{2}, \mathrm{U}_{2} \mathrm{O}_{5}$, and $\mathrm{UO}_{3}$. The analysis of the films was based on XPS and grazing incidence XRD. The results clearly show that the reducing power of the mixed plasma applied for 10 min increases with increasing $\mathrm{H}_{2}$ concentration. At the same time the oxidizing power inherent to the water plasma is diminished both in absolute and relative terms when increasing the $\mathrm{H}_{2}$ concentration. The changes in the plasma redox properties are mainly attributed to recombination reactions within the plasma generator. In all cases, the oxidation proceeds as a consecutive reaction: $\mathrm{U}(\mathrm{IV}) \leftrightarrow \mathrm{U}(\mathrm{v}) \leftrightarrow \mathrm{U}(\mathrm{vI})$. The direct transformation $\mathrm{U}(\mathrm{IV}) \leftrightarrow \mathrm{U}(\mathrm{VI})$ does not occur. This is also supported by the deconvolution result showing that the maximum concentration of $[\mathrm{U}(\mathrm{vI})]$ is reached when $[\mathrm{U}(\mathrm{Iv})]$ is at its minimum.

The XPS results show that $\mathrm{U}(\mathrm{v})$ is formed as a major product upon exposure of $\mathrm{UO}_{3}$ to a mixed $\mathrm{H}_{2} \mathrm{O} / \mathrm{H}_{2}$ plasma in a fairly wide $\mathrm{H}_{2}$ concentration range. When starting with $\mathrm{U}(\mathrm{v})\left(\mathrm{U}_{2} \mathrm{O}_{5}\right)$ appreciable $\mathrm{H}_{2}$ concentrations are needed to reduce $\mathrm{U}(\mathrm{v})$ to $\mathrm{U}(\mathrm{IV})$ in 10 minutes. In the plasma induced oxidation of $\mathrm{UO}_{2}, \mathrm{U}(\mathrm{v})$ is never observed as a major product after $10 \mathrm{~min}$ and it would seem that once $\mathrm{U}(\mathrm{v})$ is formed during the oxidation of $\mathrm{UO}_{2}$ it is rapidly oxidized further to $\mathrm{U}(\mathrm{vI})$. Formation of $\mathrm{U}(\mathrm{v})$ is easier, obtained by the reduction of $\mathrm{UO}_{3}$ by a mixed $\mathrm{H}_{2} \mathrm{O} / \mathrm{H}_{2}$ plasma. It could not be prepared by the oxidation of $\mathrm{UO}_{2}$ with the water plasma. Once $\mathrm{U}(\mathrm{v})$ is obtained from the $\mathrm{UO}_{3}$ reduction, it is relatively stable as it shows lower reactivity than $\mathrm{UO}_{2}$ for oxidation and $\mathrm{UO}_{3}$ for reduction. The grazing incidence X-ray diffraction analysis shows that there is a considerable impact of the plasma and heating conditions on the crystallographic structure of the films in line with the change of the oxidation state. This structural difference may be the main kinetic barrier for plasma induced transfer between $\mathrm{U}(\mathrm{IV})$ and $\mathrm{U}(\mathrm{v})$ in both directions. Further characterisation by micro-Raman spectroscopy and transmission electron microscopy would be helpful to identify different types of uranium oxides present on the substrate.

\section{Conflicts of interest}

There are no conflicts to declare.

\section{Acknowledgements}

The Swedish Nuclear and Fuel Waste Management Company (SKB) is gratefully acknowledged for financial support. This 
work has been partially supported by the ENEN+project that has received funding from the Euratom research and training Work Programme 2016-2017-1\#755576). E. T.-Ch. acknowledges the support of "Nano-materials Centre for Advanced Applications," Project No. CZ.02.1.01/0.0/0.0/15_003/0000485, financed by ERDF. We want to thank Prof. L. Havela for the fruitful discussion about the characterization of the films and F. Huber for the technical support.

\section{Notes and references}

1 J. Nowotny and L. C. Dufour, Mater. Sci. Monogr., 1988, 47, 275.

2 D. Rai, A. R. Felmy and J. L. Ryan, Inorg. Chem., 1990, 29, 260-264.

3 S. Svensk Kaernbraenslefoersoerjning Ab, Final storage of spent nuclear fuel - KBS-3, Swedish Nuclear Fuel Supply Co/ Div KBS, Sweden, 1983.

4 J. Bruno and R. C. Ewing, Elements, 2006, 2, 343-349.

5 H. Kleykamp, J. Nucl. Mater., 1985, 131, 221-246.

$6 \mathrm{~J}$. W. T. Spinks and R. J. Woods, An Introduction to Radiation Chemistry, 1990.

7 D. W. Shoesmith, J. Nucl. Mater., 2000, 282, 1-31.

8 D. W. Shoesmith and S. Sunder, J. Nucl. Mater., 1992, 190, 20-35.

9 F. King, L. Ahonen, C. Taxen, U. Vuorinen and L. Werme, Copper corrosion under expected conditions in a deep geologic repository, Report 1404-0344, Sweden, 2001.

10 N. R. Smart, D. J. Blackwood and L. Werme, The anaerobic corrosion of carbon steel and cast iron in artificial groundwaters, Report 1404-0344, Sweden, 2001.

11 E. Ekeroth, M. Granfors, D. Schild and K. Spahiu, J. Nucl. Mater., 2020, 531, 151981.

12 T. Eriksen and M. Jonsson, The effect of hydrogen on dissolution of spent fuel in $001 \mathrm{~mol} / \mathrm{dm}-3 \mathrm{NaHCO} 3$ solution, Report 1404-0344, Sweden, 2007.

13 P. Carbol, The effect of dissolved hydrogen on the dissolution of 233U doped UO2(s) high burn-up spent fuel and MOX fuel, Report 1404-0344, Sweden, 2005.

14 S. Röllin, K. Spahiu and U. B. Eklund, J. Nucl. Mater., 2001, 297, 231-243.

15 S. Nilsson and M. Jonsson, J. Nucl. Mater., 2008, 372, 160163.
16 M. E. Broczkowski, J. J. Noël and D. W. Shoesmith, J. Nucl. Mater., 2005, 346, 16-23.

17 S. Kastriot, L. Werme and U. B. Eklund, Radiochim. Acta, 2000, 88, 507-512.

18 N. L. Hansson, P. L. Tam, C. Ekberg and K. Spahiu, J. Nucl. Mater., 2021, 543, 152604.

19 M. Trummer, S. Nilsson and M. Jonsson, J. Nucl. Mater., 2008, 378, 55-59.

20 K. Spahiu, U.-B. Eklund, D. Cui and M. Lundström, MRS Proc., 2002, 713, JJ14.15.

21 L. Bauhn, N. Hansson, C. Ekberg, P. Fors, R. Delville and K. Spahiu, J. Nucl. Mater., 2018, 505, 54-61.

22 A. Puranen, A. Barreiro, L. Z. Evins and K. Spahiu, MRS Adv., 2017, 2, 681-686.

23 M. Jonsson, F. Nielsen, O. Roth, E. Ekeroth, S. Nilsson and M. M. Hossain, Environ. Sci. Technol., 2007, 41, 7087-7093.

24 M. Trummer, O. Roth and M. Jonsson, J. Nucl. Mater., 2009, 383, 226-230.

25 S. Nilsson and M. Jonsson, J. Nucl. Mater., 2008, 374, 290292.

26 P. Fors, P. Carbol, S. Van Winckel and K. Spahiu, J. Nucl. Mater., 2009, 394, 1-8.

27 G. El Jamal, T. Gouder, R. Eloirdi and M. Jonsson, Dalton Trans., 2021, 50, 4796-4804.

28 G. El Jamal, T. Gouder, R. Eloirdi and M. Jonsson, Dalton Trans., 2021, 50, 729-738.

29 A. Fridman, Plasma Chemistry, Cambridge University Press, 2008.

30 T. Gouder, R. Eloirdi and R. Caciuffo, Sci. Rep., 2018, 8, 8306.

31 C. A. Colmenares, Prog. Solid State Chem., 1975, 9, 139-239.

32 G. C. Allen and N. R. Holmes, J. Nucl. Mater., 1995, 223, 231-237.

33 M. Molinari, N. A. Brincat, G. C. Allen and S. C. Parker, Inorg. Chem., 2017, 56(8), 4468-4473.

34 N. C. Baenziger, Iowa State Coll. J. Sci., 1952, 27, 126-128 ISCJAF loop.

35 P. Taylor, D. D. Wood and A. M. Duclos, J. Nucl., Mater., 1992, 189, 116-123.

36 M. L. Palacios and S. H. Taylor, Appl. Spectrosc., 2000, 54, 1372-1378.

37 E. Wait and J. Inorg, Nucl. Chem., 1955, 1, 309-312.

38 B. O. Loopstra, Acta Crystallogr., Sect. B: Struct. Crystallogr. Cryst. Chem., 1970, 26, 656-657. 